\title{
Effects of restrictive-prescribing stewardship on antibiotic consumption in primary care in China: an interrupted time series analysis, 2012-2017
}

Xuemei Wang ${ }^{1}$, Yuqing Tang ${ }^{1}$, Chenxi Liu', Junjie Liu' ${ }^{2}$, Youwen Cui ${ }^{1}$ and Xinping Zhang ${ }^{1 *}$ (D)

\begin{abstract}
Background: The overuse of antibiotics has been a major public health problem worldwide, especially in low- and middle- income countries (LMIC). However, there are few policies specific to antibiotic stewardship in primary care and their effectiveness are still unclear. A restrictive-prescribing stewardship targeting antibiotic use in primary care has been implemented since December 2014 in Hubei Province, China. This study aimed to evaluate the effects of the restrictive-prescribing stewardship on antibiotic consumption in primary care so as to provide evidence-based suggestions for prudent use of antibiotics.
\end{abstract}

Methods: Monthly antibiotic consumption data were extracted from Hubei Medical Procurement Administrative Agency (HMPA) system from Sept 1, 2012, to Aug 31, 2017. Quality Indictors of European Surveillance of Antimicrobial Consumption (ESAC QIs) combined with Anatomical Therapeutic Chemical (ATC) classification codes and DDD per 1000 inhabitants per day (DID) methodology were applied to measure antibiotic consumption. An interrupted time series analysis was performed to evaluate the effects of restrictive-prescribing stewardship on antibiotic consumption.

Results: Over the entire study period, a significant reduction (32.58\% decrease) was observed in total antibiotic consumption, which declined immediately after intervention (coefficient $=-2.4518, P=0.005$ ) and showed a downward trend (coefficient $=-0.1193, P=0.017$ ). Specifically, the use of penicillins, cephalosporins and macrolides/ lincosamides/streptogramins showed declined trends after intervention (coefficient $=-0.0553, P=0.035$; coefficient $=$ $-0.0294, P=0.037$; coefficient $=-0.0182, P=0.003$, respectively). An immediate decline was also found in the contribution of $\beta$-lactamase-sensitive penicillins to total antibiotic use (coefficient $=-2.9126, P=0.001$ ). However, an immediate increase in the contribution of third and fourth-generation cephalosporins (coefficient $=5.0352, P=0.005$ ) and an ascending trend in the contribution of fluoroquinolones (coefficient $=0.0406, P=0.037$ ) were observed after intervention. The stewardship led to an immediate increase in the ratio between broad- and narrow-spectrum antibiotic use (coefficient $=1.8747, P=0.001$ ) though they both had a significant downward trend (coefficient $=$ $-0.0423, P=0.017$; coefficient $=-0.0223, P=0.006$, respectively). An immediate decline (coefficient $=-1.9292, P=0.002$ )

\footnotetext{
*Correspondence: xpzhang602@hust.edu.cn

'School of Medicine and Health Management, Tongji Medical College,

Huazhong University of Science and Technology, Wuhan, Hubei Province,

China

Full list of author information is available at the end of the article
}

C C The Author(s). 2020 Open Access This article is licensed under a Creative Commons Attribution 4.0 International License, which permits use, sharing, adaptation, distribution and reproduction in any medium or format, as long as you give appropriate credit to the original author(s) and the source, provide a link to the Creative Commons licence, and indicate if changes were made. The images or other third party material in this article are included in the article's Creative Commons licence, unless indicated otherwise in a credit line to the material. If material is not included in the article's Creative Commons licence and your intended use is not permitted by statutory regulation or exceeds the permitted use, you will need to obtain permission directly from the copyright holder. To view a copy of this licence, visit http://creativecommons.org/licenses/by/4.0/ The Creative Commons Public Domain Dedication waiver (http://creativecommons.org/publicdomain/zero/1.0/) applies to the data made available in this article, unless otherwise stated in a credit line to the data. 


\begin{abstract}
(Continued from previous page)
and a downward trend (coefficient $=-0.0815, P=0.018$ ) were also found in the oral antibiotic use after intervention, but no significant changes were observed in the parenteral antibiotic use.

Conclusions: Restrictive-prescribing stewardship in primary care was effective in reducing total antibiotic consumption, especially the use of penicillins, cephalosporins and macrolides/lincosamides/streptogramins. However, the intervention effects were limited regarding the use of combinations of penicillins with ß-lactamase inhibitors, the third and fourthgeneration cephalosporins, fluoroquinolones and parenteral antibiotics. Stronger administrative regulations focusing on specific targeted antibiotics, especially the use of broad-spectrum antibiotics and parenteral antibiotics, are in urgent need in the future.
\end{abstract}

Keywords: Antibiotic consumption, Restrictive-prescribing stewardship, Primary care, Quality indictors of European surveillance of antimicrobial consumption (ESAC QIs), Interrupted time series analysis

\section{Introduction}

Antimicrobial resistance (AMR) has been increasingly concerned as a major public health problem worldwide, leading to longer hospital stays, higher medical costs and increased mortality $[1,2]$. It was estimated that approximately 25,000 deaths in Europe, and 23,000 deaths in the USA were caused by AMR each year [3]. The health care costs resulted from antibiotic-resistant infections were as high as $\$ 20$ billion and the lost productivity was estimated to be $\$ 35$ billion per year in the US [4]. If no actions are taken, up to 10 million additional lives would be lost and the total economic burden would reach $\$ 100$ trillion by 2050 [5].

The intensive use of antibiotics has been regarded as a main driver of AMR and the unnecessary use further worsened such situation $[1,6]$. The global antibiotic consumption increased by $65 \%$ between 2000 and 2015, which was primarily driven by increased consumption in low- and middle-income countries (LMICs) [7]. It was reported that appropriately $50 \%$ of patients were prescribed antibiotics in healthcare institutions, with $30-50 \%$ regarded unnecessary and/or inappropriate [8]. It has been widely recognized that primary care should take main responsibilities because the most majority of antibiotic consumption tend to occur in primary care, which has been demonstrated by the fact that approximately half of patients attending primary care received at least one antibiotic in LMICs [9].

There are few policies specific to antibiotic stewardship in primary care and little is known about the practical effectiveness. Although previous studies have conducted some small-sale interventions to regulate antibiotic overuse in primary care, but the effects are mixed and confused. As examples, online evidencebased feedbacks effectively reduced antibiotic prescribing from 37.4 to $28.1 \%$ in patients with suspected respiratory tract infections (RTIs) attending primary care [10]. Similarly, a weekly prospective audit and feedback in three community facilities brought about a $25 \%$ immediate reduction in all antibiotic prescriptions after conducting the antibiotic stewardship and a continuous 5\% decrease over the entire intervention [11]. However, other studies showed inconsistent findings. A systematic review summarizing educational interventions to improve antibiotic prescribing showed that $62 \%$ of studies in primary care reported positive results for all measured outcomes, including total antibiotic prescription, prescribing attitudes and behaviors, and etc.; 30\% reported partial results that were not statistically significant and the remaining studies failed to report any significant improvements [12]. Further high-level evidence is needed to instruct intervention strategies in regulating antibiotic consumption in primary care.

Previous antibiotic stewardship programs in China mainly focus on secondary and tertiary hospitals, which have achieved significant improvements [13]. However, very few detailed or targeted policies are specific to antibiotic consumption in primary care, leading to a relatively poor regulation efficiency on them. For instance, an increasing trend was observed in the overall antibiotic consumption in urban primary healthcare centers in Shandong province of China, revealing an urgent need for strengthened regulation on antibiotic use in primary care [14]. Therefore, it is necessary to evaluate the intervention effects on antibiotic use in primary care, especially on some specific antibiotics, so as to supplement more targeted evidence.

A restrictive-prescribing stewardship with specified administrative regulation was issued in 2014 in Hubei province of China, aiming at further promoting prudent use of antibiotics [15]. This administrative regulation put forward detailed requirements specific to antibiotic prescribing in primary care, featured as concretely restricting antibiotic grades, varieties, prescribing rate and route of administration. This study aimed to evaluate the effects of this restrictive-prescribing stewardship on antibiotic consumption in primary care, especially with the advantage of an internationally comparable methodology of Quality Indictors of European Surveillance of Antimicrobial Consumption (ESAC QIs) [16]. 
The findings will fill the gaps in literature, especially supplementing comparable evidence on the antibiotic stewardship in primary care, so as to further promote prudent use of antibiotics.

\section{Methods}

\section{Settings and data sources}

This study was conducted in Hubei province, central China. Hubei has a population of over 61 million and covers an area of $185,900 \mathrm{~km}^{2}$. Its per capita gross domestic product (GDP) is $60,198.68$ yuan $(\$ 8915.95$ USD), ranking in the middle range of all provinces. The disposable income for rural residents and urban residents is $13,812.09$ yuan (\$2059.38 USD) and 31,889.42 yuan (\$4754.71 USD) respectively (2017). There are 36, 323 healthcare institutions in Hubei, among which 34, 742 are primary care institutions, including state-owned community or township centers [17].

Data used in this study were extracted from the Hubei Medical Procurement Administrative Agency (HMPA) system, which provided a specialized and reliable source on the medicine consumption, including antibiotics [18]. The database is targeted for primary care institutions, and monthly procurement data are recorded and updated (e.g. medicine name, procurement volume, dosage form). According to the requirements of HMPA, primary care institutions are allowed to stock and dispense medicines listed in the Essential Medicines List (EML) from its procurement platform, except for few supplementary medicines, e.g. emergency medicine. All the valid procurement records of antibiotics between September 2012 and August 2017 (except for few blank procurement records) were collected for our study.

\section{Description of the restrictive intervention}

In November 2014, a restrictive-prescribing stewardship specific to antibiotics was developed and has been formally implemented since December 2014 across the entire Hubei province. This restrictive intervention put forward strict administrative rules on the antibiotic grades, varieties, prescribing rate and route of administration in primary care. Four major requirements were involved as follows.

Firstly, all primary care institutions should comply with the requirements on using non-restricted and restricted antibiotics; only physicians with corresponding prescribing privileges are qualified to prescribe relevant grades of antibiotics; Secondly, the number of antibiotic varieties should be strictly controlled within 30 in primary care and 15 for village clinics; Thirdly, the prescribing rate of antibiotics should not exceed $20 \%$ for outpatients in rural township health centers, $40 \%$ for emergency patient, and $60 \%$ for inpatients; the Antibiotics Use Density (AUD) should not exceed 40 DDDs per 1000 inhabitants per day, and etc.; Fourthly, the route of administration of antibiotics in primary care should be mainly oral or intramuscular injection; intravenous infusion or intravenous bolus injection should be restricted to inpatient departments or outpatient observation rooms; intravenous infusion in clinics (e.g. village clinics, urban community health stations) should be approved by local health bureau.

Under the administrative power, a good policy implementation was guaranteed. Specifically, local healthcare institutions strictly execute the above four restrictive regulations by establishing and implementing antibiotic classification management system, strengthening the monitoring and management of clinical use, and enhancing the training and assessment on prescribers. Physicians follow the principles of safety, effectiveness and economy to prescribe antibiotics rationally, and only those who have received adequate training and passed assessment are granted with corresponding antibiotic prescribing privileges. Local health bureau as well as provincial health bureau are responsible for managing, supervising and evaluating the use of antibiotics. Additionally, performance appraisal are linked with rewards (e.g. salary, title appraisal), and penalties are also executed for violations of the regulations [15].

\section{Measurement of antibiotic consumption}

The Anatomical Therapeutic Chemical (ATC) classification codes were used to categorize medicines, and procurement records of 001 (antibiotics for systemic use) were extracted for the purpose of this study [19]. Defined daily dose (DDD) was used to measure the volume of antibiotics according to the WHO Collaborating Centre for Drug Statistics Methodology [20]. DDD equivalence per package (DPP) was expressed in DDD units [(unit strength $\times$ pack size)/DDD]. The summed DPPs of all-inclusive products formed the total volume for each group of antibiotic consumption (DDDs). To strengthen the comparability of antibiotic use, the DDD per 1000 inhabitants per day (DID) was eventually transformed to calculate antibiotic consumption as DID provides a measure of exposure or therapeutic intensity in a defined population, allowing comparisons across various time periods and population groups [21]. The figure "10 DID" can be explained as: 10 DDDs of the drug are averagely utilized in a representative group of 1000 inhabitants, on any given day of the year analyzed; or expressed as $1 \%$ of the population are receiving this drug each day in that year [21].

To provide drug-specific insight in measuring antibiotic consumption and trigger action to improve antibiotic use, quality indictors (QIs) proposed by European Surveillance of Antimicrobial Consumption (ESAC) were used to measure antibiotic use, which has become an internationally comparable methodology $[16,22]$. In this 
study, 10 ESAC QIs were selected into analysis and the remaining 2 ESAC QIs were not included because they were not suitable for the statistical methodology in this study. Of note, the use of narrow-spectrum antibiotics and broad-spectrum antibiotics were key indicators among ESAC QIs that deserved more attention. The narrow-spectrum antibiotics refer to the antibiotic agents that act against a limited range of potential pathogens and are often used for the specific infection when the causative agent of the infection is known, whereas broad-spectrum antibiotics are those act against a wider range of pathogenic bacteria and are more likely to kill both potential pathogens and normal flora [23-26]. Generally, narrowspectrum antibiotics are regarded more ideal than broadspectrum counterparts [25]. In this study, when calculating the ratio between broad- and narrow-spectrum antibiotic use, combinations of penicillins with ß-lactamase inhibitors, second generation cephalosporins, third generation cephalosporins and macrolides/lincosamides/streptogramins (minus erythromycin) correspond to broad-spectrum antibiotics, whereas ß-lactamse-sentitive penicillins, first generation cephalosporins and erythromycin correspond to narrow-spectrum antibiotics $[16,22]$. In addition, 4 local QIs were developed after considering the policy context in China (Table 1).

Table 1 Quality indicators of measuring antibiotic consumption in this study

\begin{tabular}{|c|c|}
\hline NO. & Quality indicators \\
\hline \multicolumn{2}{|c|}{ ESAC QIs 1-5 are the use of relevant antibiotics (expressed in DID): } \\
\hline 1 & total use of systemic antibiotics (J01) \\
\hline 2 & use of penicillins (J01C) \\
\hline 3 & use of cephalosporins (J01D) \\
\hline 4 & use of macrolides/lincosamides/streptogramins (J01F) \\
\hline 5 & use of quinolones (J01M). \\
\hline \multicolumn{2}{|c|}{ ESAC Qls 6-9 are the relative contributions (\% of total J01 use) of: } \\
\hline 6 & B-lactamse-sentitive penicillins (JO1CE) \\
\hline 7 & combinations of penicillins with B-lactamase inhibitors (J01CR) \\
\hline 8 & third and fourth generation cephalosporins (J01DD/DE) \\
\hline 9 & fluoroquinolones (J01MA) \\
\hline \multicolumn{2}{|c|}{$\begin{array}{l}\text { ESAC QI } 10 \text { is the ratio between broad- and narrow-spectrum } \\
\text { antibiotics: }\end{array}$} \\
\hline 10 & $\begin{array}{l}(J 01 C R+J 01 D C+J 01 D D+J 01 F \text { (minus J01FA01)/(J01CE + J01DB } \\
+ \text { J01FA01) }\end{array}$ \\
\hline \multicolumn{2}{|c|}{$\begin{array}{l}\text { Qls } 11-14 \text { are adapted according to the policy context in China } \\
\text { (expressed in DID): }\end{array}$} \\
\hline 11 & use of broad-spectrum antibiotics \\
\hline 12 & use of narrow-spectrum antibiotics \\
\hline 13 & use of oral antibiotics \\
\hline 14 & use of parenteral antibiotics \\
\hline
\end{tabular}

\section{Statistical analysis}

Regular, evenly spaced intervals are appropriate for a segmented regression analysis to evaluate the effect of intervention [27]. In this research, monthly antibiotic consumption from Sept 1, 2012, to Aug 31, 2017 was applied as analytical unites, of which the period from Sept 1, 2012 to December 2014 was pre-intervention evaluation period and from January, 2015 to Aug 31, 2017 was post-intervention evaluation period.

To estimate the effect of restrictive prescribing stewardship on antibiotic use, the following segmented linear regression model was applied [28]:

$$
\begin{aligned}
Y_{t}= & \beta_{0}+\beta_{1} * \text { Time }_{t}+\beta_{2} * \text { Intervention }_{t} \\
& +\beta_{3} * \text { Time after intervention }_{t} \\
& +\beta_{4} * \sin \left(2 \Pi \text { Time }_{t} / 12\right) \\
& +\beta_{5} * \cos \left(2 \Pi \text { Time }_{t} / 12\right) \varepsilon_{t}
\end{aligned}
$$

As two key parameters in the segmented linear regression, level and trend define each segment of a time series. The level is the value of the series at the beginning of a given time interval, while the trend is the rate of change of the intervention measure.

Here, $Y_{t}$ is the average number of antibiotic use in month $\mathrm{t}$; Time is a continuous variable indicating time in months at time $t$ from the start of observation; intervention is an indicator for Time $_{t}$ occurring before (intervention $=0$ ) or after (intervention $=1$ ) the cap, which was implemented at month 28 (December, 2014) in the series; and Time after intervention ${ }_{t}$ is a continuous variable counting the number of months after the intervention at time $t$, coded 0 before the cap and added by 1 continuously after the cap. The coefficients $\beta_{0}$ and $\beta_{1}$ respectively estimate the baseline level of outcome at time zero, and the change that occurs with each month before the intervention; $\beta_{2}$ and $\beta_{3}$ respectively estimate the level change in the average monthly number of antibiotic use immediately after the intervention, and the trend change of indicators after the cap, compared with the monthly trend before the cap; The sum of $\beta_{1}+\beta_{3}$ is the post intervention slope. $\beta_{4}$ and $\beta_{5}$ were used to adjust for a potential seasonality effect [29]. The error term $\varepsilon_{t}$ represents the random variable not explained by the model at time t. Considering autocorrelation may underestimate standard errors and overestimate significance of the intervention effects, it is necessary to correct for the possibility of autocorrelation [30]. The most popular test to ascertain the presence or absence of autocorrelation is Durbin-Watson test, which is a number that tests for autocorrelation in the residuals, ranging from 0 to 4 [31-33]. Values approaching 2 means that there is almost no autocorrection, whereas approaching 0 indicate positive autocorrection and approaching 4 indicate 
negative autocorrection [33]. Therefore, Durbin-Watson test was used to check for autocorrelation in this study.

All statistical analyses above were performed using STATA version 12.0 (STATA Corp, College Station, TX, USA) and $P<0.05$ was considered statistically significant.

\section{Results}

Overall antibiotic consumption over the entire study period

Over the entire study period, the total antibiotic consumption in primary care in Hubei province declined from 11.02 DID to 7.43 DID (32.58\% decrease). For penicillins and cephalosporins, the consumption respectively decreased from 5.01 DID to 2.64 DID (47.31\% decrease) and 3.08 DID to 2.54 DID (17.53\% decrease). For quinolones and macrolides/lincosamides/streptogramines, the consumption declined from 1.05 DID to 0.71 DID (32.38\% decrease) and 1.03 DID to 0.82 DID (20.39\% decrease) respectively (Fig. 1).

The relative contributions of ß-lactamse-sentitive penicillins to total antibiotic use declined from 7.78 to 4.12\% (47.04\% decrease). However, the relative contributions of penicillins with $ß$-lactamase inhibitors, third and fourth generation cephalosporins and fluoroquinolones to total antibiotic use respectively increased from 3.08 to $6.19 \%, 14.43$ to $18.13 \%$, and 9.51 to $9.56 \%$ (100.97\% increase, $25.64 \%$ increase, $0.53 \%$ increase, respectively) (Fig. 2).

The consumption of broad-spectrum antibiotics and narrow-spectrum antibiotics respectively declined from
3.82 DID to 3.20 DID (16.23\% decrease) and 1.51 DID to 0.68 DID ( $54.97 \%$ decrease). However, the ratio between broad- and narrow-spectrum antibiotic consumption increased from 2.51 to 5.09 (Fig. 3).

The consumption of oral antibiotics and parenteral antibiotics respectively declined from 5.84 DID to 3.33 DID (42.98\% decrease), and 5.18 DID to 4.09 DID (21.04\% decrease). The average decline of oral antibiotic consumption was greater than that of parenteral antibiotics over the entire study period (Fig. 4).

\section{Effects of restrictive-prescribing stewardship on antibiotic consumption}

As shown in Table 2, all of the Durbin-Watson statistics were approaching 2 , indicating that there was no autocorrelation in the observations. Before implementing the restrictive-prescribing stewardship, the consumption of total antibiotics showed an ascending trend that was not statistically significant (coefficient $=0.0237, P=0.554$ ), while the consumption declined immediately after intervention (coefficient $=-2.4518, P=0.005$ ) and had a significant downward trend (coefficient $=-0.1193, P=0.017$ ). The consumption of penicillins, macrolides/lincosamides/streptogramins, quinolones declined immediately after intervention (coefficient $=-1.9109, P<0.001$; coefficient $=-0.2248$, $P=0.030$; coefficient $=-0.2019, P=0.019$, respectively), and the consumption of penicillins, cephalosporins and macrolides/lincosamides/streptogramins showed declined trends after intervention (coefficient $=-0.0553, P=0.035$;

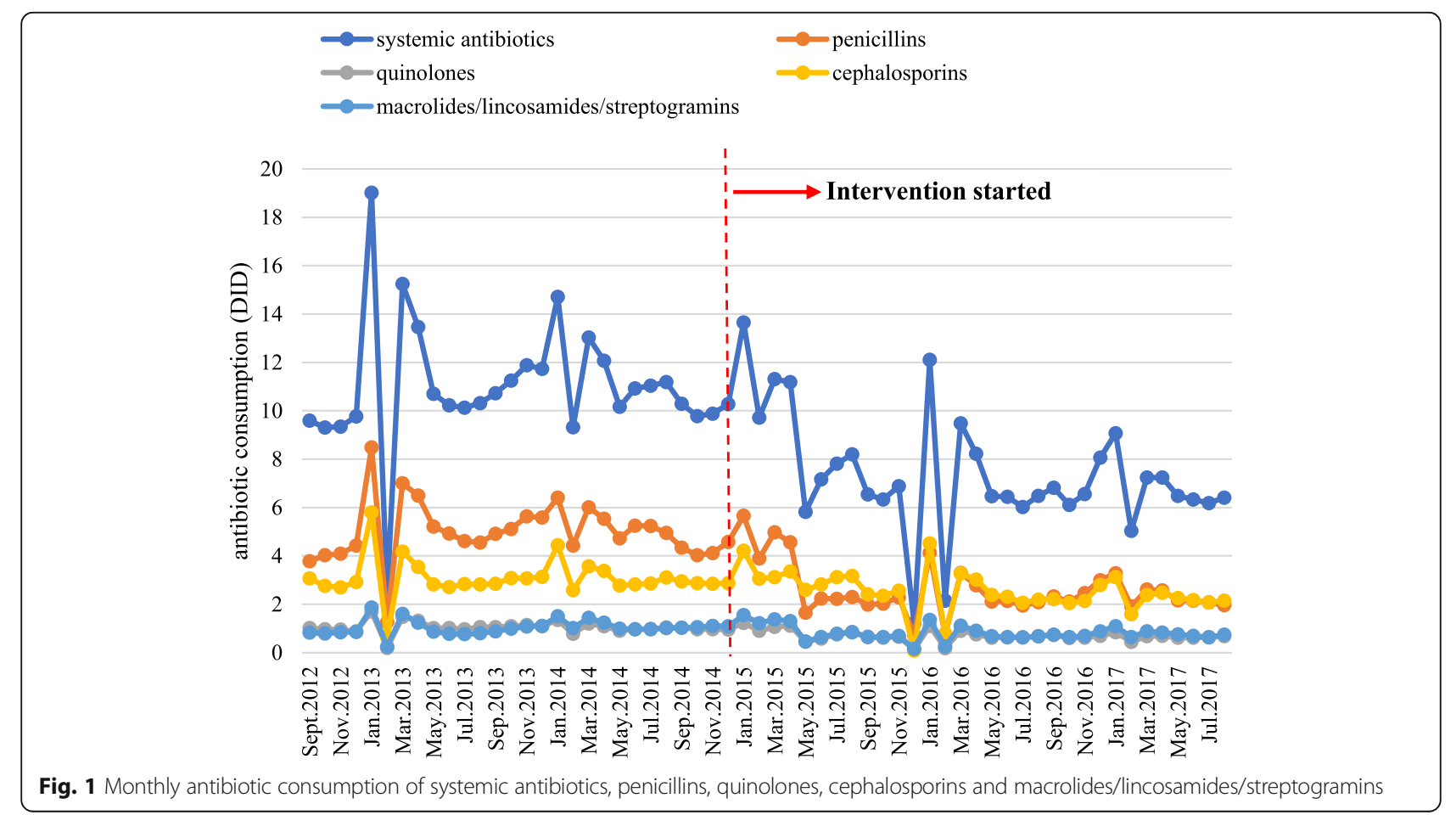




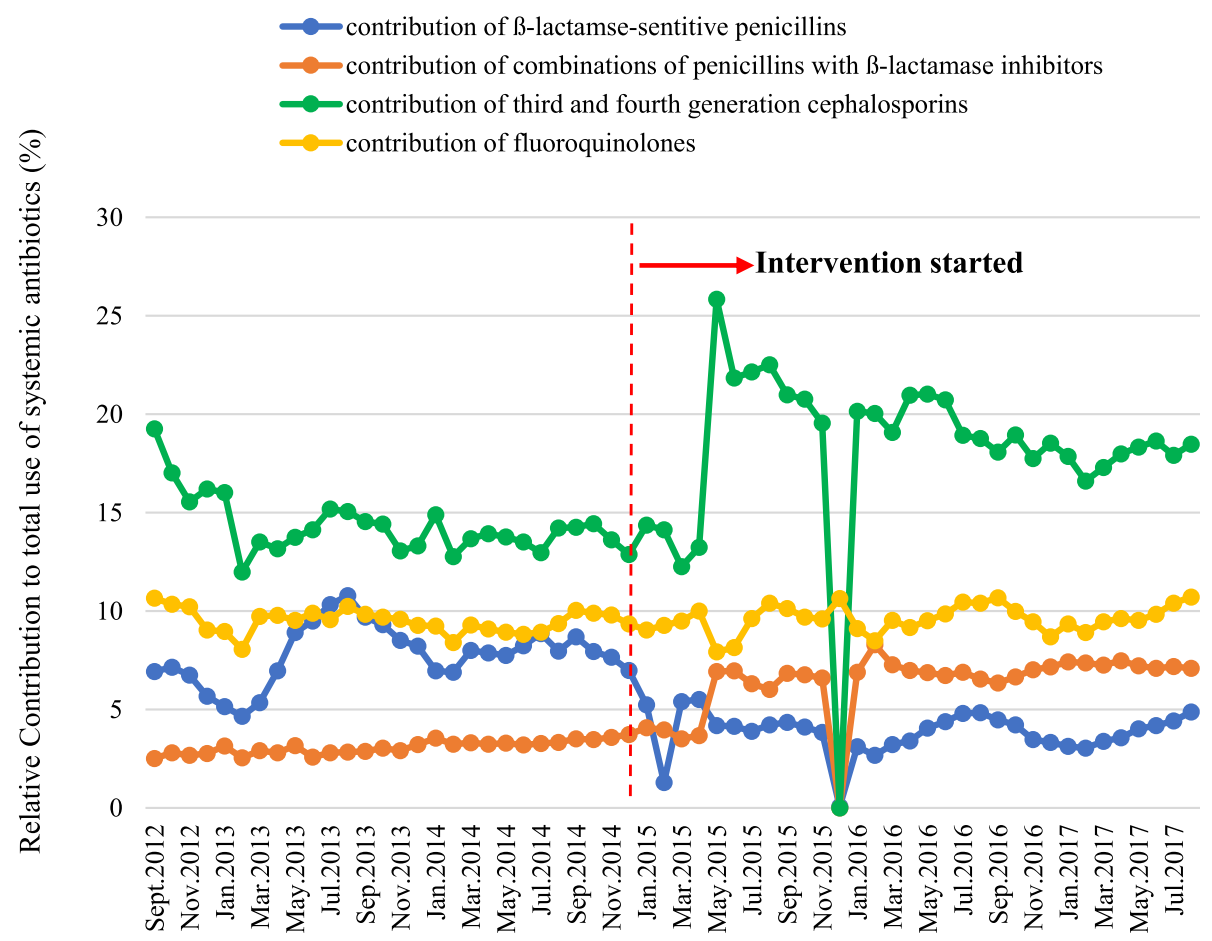

Fig. 2 Monthly relative contributions of ß-lactamse-sentitive penicillins, combinations of penicillins with ß-lactamase inhibitors, third and fourth generation cephalosporins, fluoroquinolones to total use of systemic antibiotics

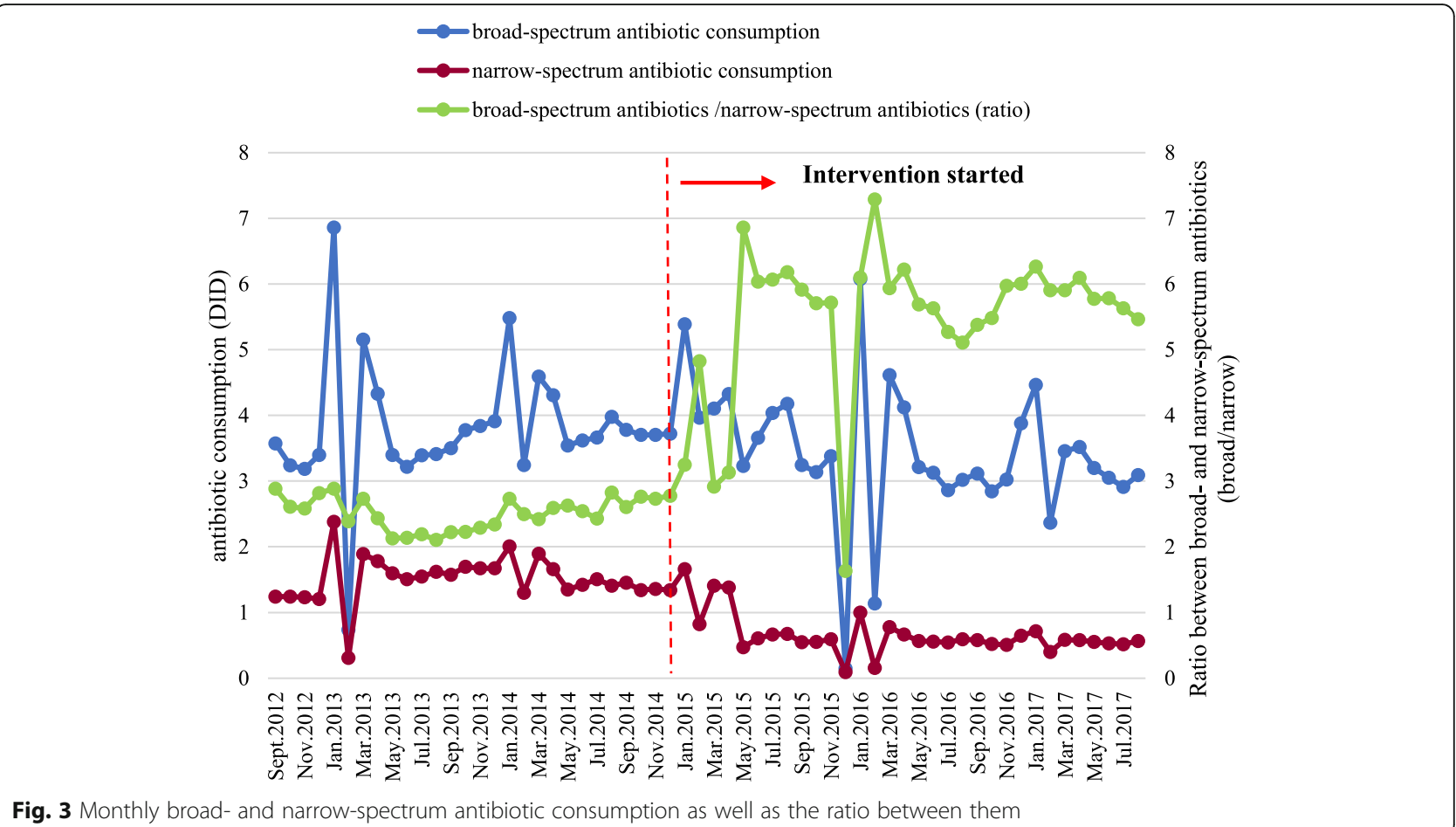

Fig. 3 Monthly broad- and narrow-spectrum antibiotic consumption as well as the ratio between them 


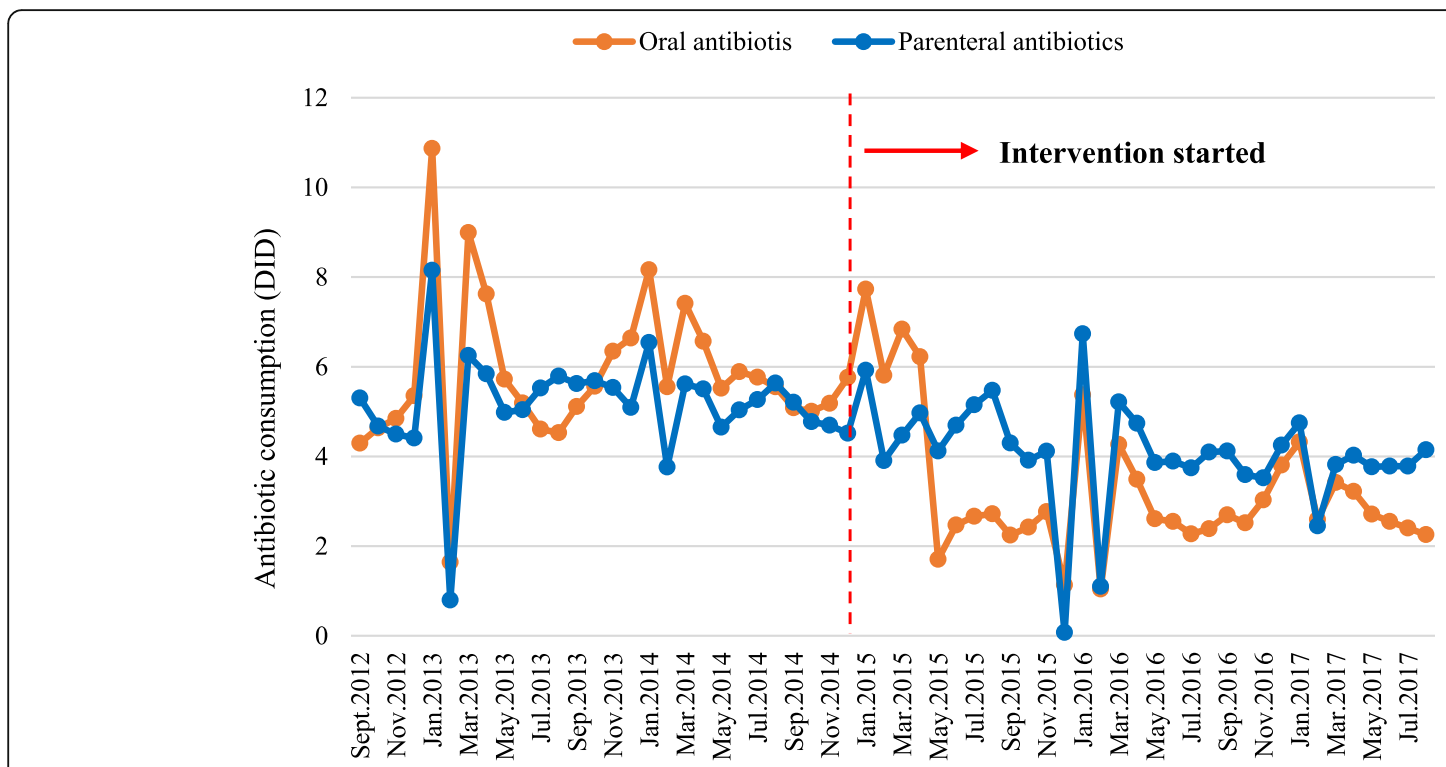

Fig. 4 Monthly antibiotic consumption of oral and parenteral antibiotics

coefficient $=-0.0294, P=0.037$; coefficient $=-0.0182, P=$ 0.003 , respectively).

The restrictive-prescribing stewardship was associated with an immediate decline in the contribution of $\beta$-lactamasesensitive penicillins to total antibiotic use (coefficient $=-2.9126, \quad P=0.001)$. However, an immediate increase was observed in the contribution of third and fourth-generation cephalosporins to total antibiotic use (coefficient $=5.0352, P=0.005$ ), and an ascending trend was found in the contribution of fluoroquinolones to total antibiotic use (coefficient $=0.0406, \quad P=0.037$ ) after intervention.

The stewardship also led to an immediate increase in the ratio between broad- and narrow-spectrum antibiotic use (coefficient $=1.8747, P=0.001$ ) though they both had a significant downward trend (coefficient $=-0.0423, P=$ 0.017; coefficient $=-0.0223, P=0.006$, respectively).

Finally, the stewardship was associated with an immediate decline in the consumption of oral antibiotics (coefficient $=-1.9292, P=0.002$ ) and a continuous downward trend (coefficient $=-0.0815, P=0.018$ ). However, no significant changes were found in the consumption of parenteral antibiotics after intervention (Table 2).

\section{Discussion}

\section{Summary of main findings}

This study confirmed that the restrictive-prescribing stewardship achieved positive effects in declining total antibiotic use, which attained the major target of the intervention. However, the intervention effects on the consumption of specific antibiotics were mixed. Although a significant decline was observed in the use of penicillins, cephalosporins, macrolides/lincosamides/streptogramins, the intervention effects on combinations of penicillins with ß-lactamase inhibitors, the third and fourth-generation cephalosporins, fluoroquinolones and parenteral antibiotics were limited, which deserved more attention and discussion.

\section{Strengths and limitations of the study}

To the best of our knowledge, it was the first study that attempted to evaluate the effects of restrictive-prescribing stewardship on antibiotic consumption in primary care, with the advantage of drug-specific quality indicators of ESAC (ESAC QIs) combined with an interrupted time series design and DID methodology.

There are several limitations in this study. First, not all antibiotics consumed in primary care institutions were included in this study. The data of non-prescribed antibiotic use (e.g. self-medication at home or over-thecounter) and prescriptions in private primary care facilities were not available in the present study. Second, the data used in this study were procurement data instead of directly extracting from the actual medicine use in each institution. However, the procurement data were based on the current practical consumption, which was approximately equivalent to the actual medicine use. Third, we are not able to assess the rationale of the cutoff value made by the government since the relevant process were not made public. Finally, clinical outcomes were not involved in this study as relevant data were not available. Future studies should focus on the safety of restrictive-prescribing stewardship (e.g. return visits, hospitalization rates and overall mortality) if clinicalrelated data are available. 
Table 2 The segmented regression analysis of intervention on antibiotic consumption

\begin{tabular}{|c|c|c|c|c|c|}
\hline & $\begin{array}{l}\text { Baseline level } \\
(95 \% \mathrm{Cl})\end{array}$ & $\begin{array}{l}\text { Baseline trend } \\
(95 \% \mathrm{Cl})\end{array}$ & $\begin{array}{l}\text { Level change after } \\
\text { intervention }(95 \% \mathrm{Cl})\end{array}$ & $\begin{array}{l}\text { Trend change after } \\
\text { intervention }(95 \% \mathrm{Cl})\end{array}$ & DW \\
\hline \multicolumn{6}{|l|}{ Use of relevant antibiotics (expressed in DID) } \\
\hline Systemic antibiotics & $\begin{array}{l}10.7777^{* * *} \\
(9.51,12.05)\end{array}$ & $\begin{array}{l}0.0237 \\
(-0.06,0.10)\end{array}$ & $\begin{array}{l}-2.4518^{* *} \\
(-4.14,-0.76)\end{array}$ & $\begin{array}{l}-0.1193^{*} \\
(-0.22,-0.02)\end{array}$ & 2.0572 \\
\hline Penicillins & $\begin{array}{l}4.8920^{* * *} \\
(4.22,5.56)\end{array}$ & $\begin{array}{l}0.0124 \\
(-0.03,0.05)\end{array}$ & $\begin{array}{l}-1.9109^{* * *} \\
(-2.80,-1.02)\end{array}$ & $\begin{array}{l}-0.0553^{*} \\
(-0.11,-0.00)\end{array}$ & 1.9703 \\
\hline Cephalosporins & $\begin{array}{l}3.1150^{* * *} \\
(2.75,3.48)\end{array}$ & $\begin{array}{l}-0.0015 \\
(-0.02,0.02)\end{array}$ & $\begin{array}{l}-0.0262 \\
(-0.51,0.45)\end{array}$ & $\begin{array}{l}-0.0294^{*} \\
(-0.06,-0.00)\end{array}$ & 2.2194 \\
\hline Macrolides/lincosamides/ streptogramins & $\begin{array}{l}0.9053^{* * *} \\
(0.75,1.06)\end{array}$ & $\begin{array}{l}0.0099^{*} \\
(0.00,0.02)\end{array}$ & $\begin{array}{l}-0.2248^{*} \\
(-0.43,-0.02)\end{array}$ & $\begin{array}{l}-0.0182^{* *} \\
(-0.03,-0.01)\end{array}$ & 1.9409 \\
\hline Quinolones & $\begin{array}{l}1.0594^{* * *} \\
(0.93,1.19)\end{array}$ & $\begin{array}{l}-0.0005 \\
(-0.01,0.01)\end{array}$ & $\begin{array}{l}-0.2019^{*} \\
(-0.37,-0.03)\end{array}$ & $\begin{array}{l}-0.0077 \\
(-0.02,0.00)\end{array}$ & 2.0270 \\
\hline \multicolumn{6}{|l|}{ Relative contributions (\% of total J01 use) } \\
\hline B-lactamse-sentitive penicillins & $\begin{array}{l}7.2141^{* * *} \\
(5.86,8.57)\end{array}$ & $\begin{array}{l}0.0271 \\
(-0.06,0.11)\end{array}$ & $\begin{array}{l}-2.9126^{* *} \\
(-4.55,-1.27)\end{array}$ & $\begin{array}{l}-0.0825 \\
(-0.19,0.03)\end{array}$ & 2.0439 \\
\hline $\begin{array}{l}\text { Combinations of penicillins with B-lactamase } \\
\text { inhibitors }\end{array}$ & $\begin{array}{l}2.6349^{* * *} \\
(1.71,3.56)\end{array}$ & $\begin{array}{l}0.0312 \\
(-0.03,0.09)\end{array}$ & $\begin{array}{l}1.2010 \\
(-0.01,2.41)\end{array}$ & $\begin{array}{l}0.0618 \\
(-0.01,0.13)\end{array}$ & 1.9534 \\
\hline Third and fourth generation cephalosporins & $\begin{array}{l}16.2036^{* * *} \\
(13.55,18.85)\end{array}$ & $\begin{array}{l}-0.1312 \\
(-0.30,0.03)\end{array}$ & $\begin{array}{l}5.0352^{* *} \\
(1.55,8.52)\end{array}$ & $\begin{array}{l}0.1543 \\
(-0.05,0.36)\end{array}$ & 1.9815 \\
\hline Fluoroquinolones & $\begin{array}{l}9.7988^{* * *} \\
(9.31,10.29)\end{array}$ & $\begin{array}{l}-0.0246 \\
(-0.05,0.01)\end{array}$ & $\begin{array}{l}0.2156 \\
(-0.42,0.85)\end{array}$ & $\begin{array}{l}0.0406^{*} \\
(0.00,0.08)\end{array}$ & 1.8880 \\
\hline \multicolumn{6}{|l|}{$\begin{array}{l}\text { Use of Broad-and narrow-spectrum antibiotics } \\
\text { (expressed in DID) }\end{array}$} \\
\hline Broad & $\begin{array}{l}3.6089^{* * *} \\
(3.16,4.06)\end{array}$ & $\begin{array}{l}0.0148 \\
(-0.01,0.04)\end{array}$ & $\begin{array}{l}-0.1212 \\
(-0.72,0.48)\end{array}$ & $\begin{array}{l}-0.0423^{*} \\
(-0.08,-0.01)\end{array}$ & 2.2142 \\
\hline Narrow & $\begin{array}{l}1.4481^{* * *} \\
(1.24,1.65)\end{array}$ & $\begin{array}{l}0.0055 \\
(-0.01,0.02)\end{array}$ & $\begin{array}{l}-0.6449^{* * *} \\
(-0.92,-0.37)\end{array}$ & $\begin{array}{l}-0.0223^{* *} \\
(-0.04,-0.01)\end{array}$ & 1.9398 \\
\hline \multicolumn{6}{|l|}{$\begin{array}{l}\text { Ratio between broad-narrow spectrum antibiotic } \\
\text { use (ratio) }\end{array}$} \\
\hline Broad /Narrow & $\begin{array}{l}2.4977^{* * *} \\
(1.65,3.34)\end{array}$ & $\begin{array}{l}0.0032 \\
(-0.05,0.06)\end{array}$ & $\begin{array}{l}1.8747^{* *} \\
(0.78,2.97)\end{array}$ & $\begin{array}{l}0.0500 \\
(-0.02,0.12)\end{array}$ & 1.9345 \\
\hline \multicolumn{6}{|l|}{$\begin{array}{l}\text { Use of oral and parenteral antibiotics } \\
\text { (expressed in DID) }\end{array}$} \\
\hline Oral & $\begin{array}{l}5.6076^{* * *} \\
(4.73,6.48)\end{array}$ & $\begin{array}{l}0.0221 \\
(-0.03,0.08)\end{array}$ & $\begin{array}{l}-1.9292^{* *} \\
(-3.09,-0.77)\end{array}$ & $\begin{array}{l}-0.0815^{*} \\
(-0.15,-0.01)\end{array}$ & 1.9424 \\
\hline Parenteral & $\begin{array}{l}5.1721^{* * *} \\
(4.63,5.71)\end{array}$ & $\begin{array}{l}0.0011 \\
(-0.03,0.03)\end{array}$ & $\begin{array}{l}-0.5049 \\
(-1.22,0.21)\end{array}$ & $\begin{array}{l}-0.0373 \\
(-0.08,0.00)\end{array}$ & 2.2052 \\
\hline
\end{tabular}

Notes: ${ }^{*} p<0.05 ;{ }^{* *} p<0.01 ;{ }^{* * *} p<0.001$;

$\mathrm{Cl}$ Confidence intervals, DW Durbin-Watson

\section{Comparison with existing literature}

This study confirmed that the restrictive-prescribing stewardship was associated with a significant reduction in total antibiotic consumption, indicating that the stewardship achieved success to a large extent. As pointed out by Coenen S et al. [16], "total use of systemic antibiotics expressed in DID" was regarded as the most useful indicator as it could best represent the size of pressure driving AMR, thus the reduction in total antibiotic use in our study indicated a lessening pressure driving resistance. Contrast with our findings, Borde JP et al. [34] found that the total antibiotic use expressed in DID increased by $2 \%$ in Germany after implementing an intensified antibiotic stewardship (aiming at a $>30 \%$ reduction of cephalosporin and fluoroquinolone use within 1 year), which indicated that stewardship targeting only several antibiotics may be insufficient to decrease the total antibiotic use.

With regard to the use of penicillins, it was recommended that the use of cephalosporins, macrolides/lincosamides/streptogramins, quinolones should be assessed together [16]. Along with the declined use of penicillins after intervention, the use of cephalosporins, macrolides/ lincosamides/streptogramins also achieved significant reduction, indicating relevant practice is getting better as the latter antibiotics acted as second-line drugs with 
limited evidence of additional clinical benefit over penicillins for the most common indication [16].

Of note, the contribution of $\beta$-lactamase-sensitive penicillins to total antibiotic use showed an immediate decline after intervention, while an increase was observed in the contribution of combinations of penicillins with ß-lactamase inhibitors though there was no statistical significance, which was similar with the phenomenon in European countries that a shift from the use of narrow-spectrum antibiotics towards combinations of penicillins with ß-lactamase inhibitors [35].

In addition, similar to the declined cephalosporin use in our study, Borde JP et al. [34] found that the use of cephalosporins expressed in DID declined by $26 \%$ after implementing an intensified antibiotic stewardship targeting cephalosporin and fluoroquinolone use, indicating interventions focusing on specific antibiotics would be more targeted and effective to reduce corresponding antibiotic use. However, an immediate increase was observed in the contribution of third and fourth-generation cephalosporins in our study, indicating a relatively poor practice. One reason may lie in that third-generation cephalosporins were frequently prescribed for common infections by general physicians, while the prescribing habits were usually difficult to change [36]. Another reason may because the third and fourth-generation cephalosporins could be generally used when patients had immunoglobulin E-mediated response (anaphylaxis) to penicillin, which may also result in an increase of third and fourth-generation cephalosporin use [37].

Regarding the use of quinolones, it was worth noting that fluoroquinolone was the only quinolone product used in primary care of Hubei Province. In this study, though fluoroquinolone use showed an absolute decrease, the subsequent downward trend was nonsignificant, and an ascending trend was found in the contribution of fluoroquinolones, illustrating that the regulatory control on fluoroquinolone use need to be further strengthened. Consistent with our findings, Rodrigues AT et al. [38] found that relative prescription of fluoroquinolones showed no changes after intervention, which were attributed to the association of these prescriptions in primary care with disease condition and patient's age, making it more difficult to change prescribing behaviors in such cases. Jindai $\mathrm{K}$ et al. [39] discovered an initial reduction on fluoroquinolone prescribing rate after implementing fluoroquinolone safety initiative but was not sustained later, calling for sustainable strategies. Future stewardship should not only specifically target fluoroquinolone use but also combine ongoing approaches to enhance the sustainability of intervention.

Another interesting finding in this study was that along with the reduction of total antibiotic use, an increase of the ratio between broad- and narrow-spectrum antibiotic use was observed after intervention, though there was a significant downward trend respectively in the use of broad- and narrow-spectrum antibiotics. This finding was consistent with a previous study by $\mathrm{Li} \mathrm{H}$ et al. [40] that the percentage of broad-spectrum antibiotic prescriptions did not achieve significant decline after intervention, which were attributed to less attention on the appropriateness of antibiotic types. Based on the comparison with other previous studies [38, 41-46], the increase of the ratio between broad- and narrowspectrum antibiotic use in this study may result from the following reasons. First, our restrictive-prescribing stewardship lacked multi-faceted intervention (e.g. a multidisciplinary approach involving physicians, pharmacists and patients simultaneously) and was not targeted on some specific excessively-used broad-spectrum antibiotics. Second, our stewardship neglected advocating guideline-recommended alternative antibiotics, especially relevant narrow-spectrum alternatives, to replace those excessively-used broad-spectrum antibiotics. Third, the consumption of broad-spectrum antibiotics has always occupied a major proportion of total antibiotics and presented a dramatical increase, making it more difficult to decline the ratio between broad- and narrow-spectrum antibiotic use. Fourth, broad-spectrum antibiotics are usually inappropriately preferred even in the instances that narrow-spectrum counterparts maybe more suitable, and physicians tend to broaden empiric antibacterial therapy especially when facing patients with worsening condition. Finally, in some cases (e.g. neutropenic sepsis), physicians generally tried empiric broad-spectrum therapy at the beginning before the microbiological test results were known, which may also increase the difficulty of reducing broad-spectrum antibiotic use.

Moreover, the stewardship failed to make significant progress in regulating parenteral antibiotic use, though significant decline were found in oral antibiotic use. Contrast with our findings, Hersh AL et al. [47] found a decline in parenteral antibiotic use after implementing an outpatient parenteral antibiotic therapy (OPAT) stewardship program, which may attribute to the more targeted stewardship specific to parenteral antibiotics. The overuse of injections has become common concerns in many LMICs and may result in unexpected outcomes [48]. However, a wide belief still existed in many cultures that injection is a quite powerful method for health, driving patients preferring injections to oral medicines [49]. Not only that, physicians are more likely to prescribe injections to satisfy patients' demands and earn a higher salary due to their higher prices [49].

\section{Policy implications}

It is a well-known fact that the overuse of antibiotics is increasingly regarded as a main pressure driving resistance, 
resulting in a cost to human lives and healthcare resources $[1,2]$. Restrictive-prescribing stewardship successfully regulated the excessive use of antibiotics overall. However, regarding the use of combinations of penicillins with Blactamase inhibitors, the third and fourth-generation cephalosporins, fluoroquinolones and parenteral antibiotics, a stronger and more targeted antibiotic stewardship involving multidisciplinary approaches is needed. Future stewardship focusing on targeted antibiotics especially the use of broad-spectrum antibiotics and parenteral antibiotics, combined with multi-faceted ongoing interventions are warranted to achieve sustainable improvement.

\section{Conclusion}

Restrictive-prescribing stewardship in primary care achieved significant effects in reducing total antibiotic consumption, indicating a major success of the intervention to a large extent. Practice regarding the use of penicillins, cephalosporins, macrolides/lincosamides/streptogramins are getting better overall, whereas the intervention effects on combinations of penicillins with $ß$-lactamase inhibitors, the third and fourth-generation cephalosporins, fluoroquinolones and parenteral antibiotics were limited. Stronger regulation with a multidisciplinary approach should be strengthened to focus on the use of targeted antibiotics, especially broad-spectrum antibiotics and parenteral antibiotics. Future studies are warranted to explore the potential influencing factors of limited effects on those antibiotics and accordingly design a stronger and more targeted antibiotic stewardship strategy.

\section{Abbreviations}

ATC: Anatomical Therapeutic Chemical classification; DID: DDD per 1000 inhabitants per day; ESAC QIs: Quality Indictors of European Surveillance of Antimicrobial Consumption; J01: Antibiotics for systemic use; J01C: Penicillins; J01D: Cephalosporins; J01F: Macrolides/lincosamides/streptogramins; J01M: Quinolones; J01CE: ß-lactamse-sentitive penicillins; J01CR: Combinations of penicillins with B-lactamase inhibitors; J01DD/ DE: Third and fourth generation cephalosporins; J01MA: Fluoroquinolones; J01DC: Second generation cephalosporins; J01FA01: Erythromycin; J01DB: First generation cephalosporins; Cl: Confidence intervals; DW: DurbinWatson

\section{Acknowledgements}

The authors would like to sincerely thank the help and support provided by members involved in this article, especially the valuable and professional suggestions on poster abstract by the editors of 2019 Lancet-CAMS Health Conference.

\section{Authors' contributions}

XW contributed to the study design, data analysis, and drafting of the manuscript. YT was involved in the conception and revision of the manuscript. $C L$ and $J L$ participated in the revision of the manuscript. $Y C$ participated in the extraction and interpretation of the data. XZ and YT made substantial contributions to the conception, design, and revision of the manuscript. All authors have seen and approved the final version of this article for publication.

\section{Funding}

This study was founded by the National Natural Science Foundation of China Youth Fund (grant number 71704058).

\section{Availability of data and materials}

The original data used in this study were extracted from the Hubei Medical Procurement Administrative System (HMPAS), which is a publicly available platform.

Ethics approval and consent to participate

A prior abstract about part of the findings was submitted for the 2019 Lancet-CAMS Health Conference held in China, and it was accepted and printed on the conference brochure and posters [50]. However, the full manuscript has never been submitted or published in the Lancet journal or elsewhere. According to the ethics and consent, we have cited the published abstract in this article.

\section{Consent for publication}

Consent for publication was obtained from each participant prior to the research, and the formal full manuscript was also allowed for publication in other journals by the 2019 Lancet-CAMS Health Conference.

\section{Competing interests}

The authors declare no conflict of interest.

\section{Author details}

${ }^{1}$ School of Medicine and Health Management, Tongji Medical College, Huazhong University of Science and Technology, Wuhan, Hubei Province, China. ${ }^{2}$ School of Statistics and Mathematics, Central University of Finance and Economics, Beijing, China.

Received: 3 July 2020 Accepted: 21 September 2020

Published online: 25 September 2020

\section{References}

1. Goossens H, Ferech M, Stichele RV, Elseviers M. Outpatient antibiotic use in Europe and association with resistance: a cross-national database study. Lancet. 2005:365(9459):579-87.

2. Laxminarayan R, Duse A, Wattal C, Zaidi AKM, Wertheim HFL, Sumpradit N, Vlieghe E, Hara GL, Gould IM, Goossens H, Greko C, So AD, Bigdeli M,

Tomson G, Woodhouse W, Ombaka E, Peralta AQ, Qamar FN, Mir F, Kariuki S, Bhutta ZA, Coates A, Bergstrom R, Wright GD, Brown ED, Cars O. Antibiotic resistance- the need for global solutions. Lancet Infect Dis. 2013; 13(12):1057-98.

3. Sabtu N, Enoch DA, Brown NM. Antibiotic resistance: what, why, where, when and how? Br Med Bull. 2015;116:105-13.

4. Golkar Z, Bagasra O, Pace DG. Bacteriophage therapy: a potential solution for the antibiotic resistance crisis. J Infect Dev Countr. 2014;8(2):129-36.

5. Jasovský D, Littmann J, Zorzet A, Cars O. Antimicrobial resistance-a threat to the world's sustainable development. Ups J Med Sci. 2016;121(3):159-64.

6. Malone SM, Seigel N, Newland JG, Saito JM, McKay VR. Understanding antibiotic prophylaxis prescribing in pediatric surgical specialties. Infect Control Hosp Epidemiol. 2020;41(6):666-71.

7. Klein EY, Van Boeckel TP, Martineza EM, Panta S, Gandraa S, Levine SA, Goossensh H, Laxminarayan R. Global increase and geographic convergence in antibiotic consumption between 2000 and 2015. Proc Natl Acad Sci U S A; 2018. 2018;115(15):E3463-70.

8. Spivak ES, Cosgrove SE, Arjun S. Measuring appropriate antimicrobial use: attempts at opening the black box. Clin Infect Dis. 2016;63:1639-44.

9. Sulis G, Adam P, Nafade V, Gore G, Daniels B, Daftary A, Das J, Gandra S, Pai M. Antibiotic prescription practices in primary care in low- and middleincome countries: A systematic review and meta-analysis. PLoS Med. 2020; 17(6):e1003139.

10. Urbiztondo I, Bjerrum L, Caballero L, Suarez MA, Olinisky M, Córdoba G. Decreasing inappropriate use of antibiotics in primary Care in Four Countries in South America_cluster randomized controlled trial. J Antibiot. 2017;6(4):38

11. Doernberg SB, Dudas $V$, Trivedi KK. Implementation of an antimicrobial stewardship program targeting residents with urinary tract infections in three community long-term care facilities: a quasi-experimental study using time-series analysis. Antimicrob Resist Infect Control. 2015;4:54.

12. Roque F, Herdeiro MT, Soares S, Rodrigues AT, Breitenfeld L, Figueiras A. Educational interventions to improve prescription and dispensing of antibiotics: a systematic review. BMC Public Health. 2014;14:1276. 
13. Bao L, Peng R, Wang Y, Ma R, Ren X, Meng W, Sun F, Fang J, Chen P, Wang Y, Chen Q, Cai J, Jin J, Guo J, Yang S, Mo X, Zhang E, Zhang Y, Lu Z, Chen B, Yue X, Zhu M, Wang Y, Li X, Bian Y, Kong S, Pan W, Ding Q, Cao J, Liu R, Chen N, Huang X, B A, Lyu H. Significant reduction of antibiotic consumption and patients' costs after an action plan in China, 2010-2014. PLoS One. 2015;10(3):e0118868.

14. Yin J, Li Q, Sun Q. Antibiotic consumption in Shandong Province, China: an analysis of provincial pharmaceutical centralized bidding procurement data at public healthcare institutions, 2012-16. J Antimicrob Chemother. 2018;73: 814-20.

15. Health Commission of Hubei Province. Notice on the issuance of the "Administrative Measures for the Provision and Use of Essential Medicines in Medical and Health Institutions in Hubei Province". http://www.hbjycg.com: 83/eWebEditor/uploadfile/20150205165603903.pdf. Accessed 8 Apr 2019.

16. Coenen S, Ferech M, Haaijer-Ruskamp FM, Butler CC, Stichele RHV, Verheij TJM, Monnet DL, Goossens H. The ESAC project group. European surveillance of antimicrobial consumption (ESAC): quality indicators for outpatient antibiotic use in Europe. Qual Saf Health Care. 2007;16(6):440-5.

17. Hubei Provincal Bureau of Statistics. Statistical Yearbook. http://tj..hubei.gov. cn/tjsj/sjkscx/tjnj/qstjnj/. Accessed 23 Apr 2019.

18. Hubei Medical Procurement Administrative Agency (HMPA). Centralized online drug procurement in primary care institutions in Hubei Province. http://www.hbjycg.com:83/HomePage/ShowList.aspx?Catalogld=40. Accessed 5 Apr 2019.

19. WHO. WHO methodology for a global programme on surveillance of antimicrobial consumption. https://www.who.int/medicines/areas/rational_ use/WHO_AMCsurveillance_1.0.pdf. Accessed 15 Apr 2019.

20. WHOCC. ATC/DDD Index and Guidelines. https://www.whocc.no/atc_ddd_ index/. Accessed 8 Apr 2019.

21. WHO. Essential medicines and health products. https://www.who.int/ medicines/regulation/medicines-safety/toolkit_indicators/en/. Accessed 30 Aug 2020.

22. Velden AW, Roukens M, Garde EV, Lourens M, Natsch S. Usefulness of quality indicators for antibiotic use: case study for the Netherlands. Int $J$ Qual Health Care. 2016;28(6):838-42.

23. Melander RJ, Zurawski DV, Melander C. Narrow-Spectrum antibacterial agents. MedChemComm. 2018;9(1):12-21.

24. Sarpong EM, Miller GE. Narrow- and broad-Spectrum antibiotic use among U.S. children. Health Serv Res. 2015;50(3):830-46.

25. Ullah $\mathrm{H}$, Ali S. Classification of anti-bacterial agents and their functions. Antibacterial Agents. 2017. https://doi.org/10.5772/intechopen.68695.

26. Saene RV, Fairclough S, Petros A. Broad- and narrow-spectrum antibiotics: a different approach. Clin Microbiol Infect. 1998;4:56-7.

27. Wagner AK, Soumerai SB, Zhang F, Ross-Degnan D. Segmented regression analysis of interrupted time series studies in medication use research. J Clin Pharm Ther. 2002;27(4):299-309.

28. Tang Y, Liu C, Zhang Z, Zhang X. Effects of prescription restrictive interventions on antibiotic procurement in primary care settings: a controlled interrupted time series study in China. Cost Eff Resour Alloc. 2018;16:1.

29. Chandy SJ, Naik GS, Charles R, Jeyaseelan V, Naumova EN, Thomas K, Lundborg CS. The impact of policy guidelines on hospital antibiotic use over a decade: a segmented time series analysis. PLoS One. 2014;9(3): e92206.

30. Davey P, Brown E, Charani E, Fenelon L, Gould IM, Holmes A, Ramsay CR, Wiffen PJ, Wilcox M. Interventions to improve antibiotic prescribing practices for hospital inpatients. Cochrane Database Syst Rev. 2013;4: CD003543.

31. Huitema BE, Mckean JW. Identifying autocorrelation generated by various error processes in interrupted time-series regression designs: a comparison of AR1 and portmanteau tests. Educ Psychol Meas. 2007;67(3):447-59.

32. Durbin J, Watson GS. Testing for serial correlation in least squares regression I. Biometrika. 1950;37:409-28.

33. Draper NR, Smith H. Applied regression analysis. Wiley Series in Probability and Statistics. 1998. https://doi.org/10.1002/9781118625590.

34. Borde JP, Litterst S, Ruhnke M, Feik R. Hübner J, deWith K, Kaier K, Kern WV. Implementing an intensified antibiotic stewardship programme targeting cephalosporin and fluoroquinolone use in a 200-bed community hospital in Germany. Infection. 2015;43(1):45-50.

35. Versporten A, Coenen S, Adriaenssens N, Muller A, Minalu G, Faes C, Vankerckhoven V, Aerts M, Hens N, Molenberghs G, Goossens H. European
Surveillance of Antimicrobial Consumption (ESAC): outpatient penicillin use in Europe (1997-2009). J Antimicrob Chemother. 2011;66:vi13-23.

36. Wang S, Pulcin C, Rabaud C, Boivin JM, Birgé J. Inventory of antibiotic stewardship programs in general practice in France and abroad. Med Mal Infect. 2015;45:111-23.

37. Campagna JD, Bond MC, Schabelman E, Hayes BD. The use of Cephalosporins in penicillin-allergic patients: a literature review. J Emerg Med. 2012;42(5):612-20.

38. Rodrigues AT, Roque F, Pineirolamas M, Falcao A, Figueiras A, Herdeiro MT. Effectiveness of an intervention to improve antibiotic-prescribing behaviour in primary care: a controlled, interrupted time-series study. J Antimicrob Chemother. 2019;74(9):2788-96.

39. Jindai K, Goto M, MacKay K, Forrest GN, Musuuza J. PhD6, Safdar N, Pfeiffer $\mathrm{CD}$. Improving fluoroquinolone use in the outpatient setting using a patient safety initiative. Infect Control Hosp Epidemiol. 2018;39:1108-11.

40. Li H, Gong YH, Han J, Zhang SC, Chen SQ, Xu X, Lu ZX, Yin XX. Interrupted Time-Series Analysis to Evaluate the Impact of a National Antimicrobial Stewardship Campaign on Antibiotic Prescribing: A Typical Practice in China's Primary Care. Clin Infect Dis. 2020:ciaa962. https://doi.org/10.1093/ $\mathrm{cid} / \mathrm{ciaa962}$

41. Hernandezsantiago V, Marwick C, Patton A, Davey PG, Donnan PT, Guthrie B. Time series analysis of the impact of an intervention in Tayside, Scotland to reduce primary care broad-spectrum antimicrobial use. J Antimicrob Chemother. 2015;70(8):2397-404.

42. Aabenhus R, Siersma V, Hansen MP, Bjerrum L. Antibiotic prescribing in Danish general practice 2004-13. J Antimicrob Chemother. 2016;71(8):2286-94.

43. Kourlaba G, Gkraniaklotsas E, Kourkouni E, Mavrogeorgos G, Zaoutis T. Antibiotic prescribing and expenditures in outpatient adults in Greece, 2010 to 2013: evidence from real-world practice. Eurosurveillance. 2016;21(26):1-9.

44. Hersh AL, Jackson MA, Hicks LA. Principles of judicious antibiotic prescribing for upper respiratory tract infections in pediatrics. Pediatrics. 2013;132(6): 1146-54.

45. Van Boeckel TP, Gandra S, Ashok A, Caudron Q, Grenfell BT, Levin SA, Laxminarayan R. Global antibiotic consumption 2000 to 2010: an analysis of national pharmaceutical sales data. Lancet Infect Dis. 2014;14(8):742-50.

46. Friedman N, Temkin E, Carmeli Y. The negative impact of antibiotic resistance. Clin Microbiol Infect. 2016:22(5):416-22.

47. Hersh AL, Olson J, Stockmann C, Thorell EA, Knackstedt ED, Esquibel L, Sanderson S, Pavia AT. Impact of antimicrobial stewardship for pediatric outpatient parenteral antibiotic therapy. J Pediat Inf Dis Soc. 2018;7(2):e34-6.

48. Soleymani F, Rashidian A, Hosseini M, Dinarvand R, Kebriaeezade A, Abdollahi M. Effectiveness of audit and feedback in addressing over prescribing of antibiotics and injectable medicines in a middle-income country: an RCT. DARU. 2019;27(1):101-9.

49. Cheraghali AM, Solemani F, Behmanesh $Y$, Habibipour F, Ismaeilzadeh $A$, Nikfar S, Rahimi W. Physicians' attitude toward injectable medicine. J Pharmacol Toxicol. 2006;1 (1):33-9.

50. Wang $X$, Tang $Y$, Liu C, Liu J, Cui Y, Zhang X. Effects of restrictive prescribing on antibiotic consumption in primary care in China, 2012-17: an interrupted time-series analysis. The Lancet-CAMS Health Summit. 2019;394(Supple 1): S97.

\section{Publisher's Note}

Springer Nature remains neutral with regard to jurisdictional claims in published maps and institutional affiliations.

\section{Ready to submit your research? Choose BMC and benefit from:}

- fast, convenient online submission

- thorough peer review by experienced researchers in your field

- rapid publication on acceptance

- support for research data, including large and complex data types

- gold Open Access which fosters wider collaboration and increased citations

- maximum visibility for your research: over $100 \mathrm{M}$ website views per year

At BMC, research is always in progress.

Learn more biomedcentral.com/submission 